\title{
Scientometric indicators for Brazilian research on High Energy Physics, 1983-2013
}

\author{
GONZALO R. ALVAREZ ${ }^{1}$, SAMILE A.S. VANZ ${ }^{1}$ and MARCIA C. BARBOSA ${ }^{2}$ \\ ${ }^{1}$ Universidade Federal do Rio Grande do Sul, Faculdade de Biblioteconomia e Comunicação, Programa de Pós- \\ Graduação em Comunicação e Informação, Av. Ramiro Barcelos, 2705, 90035-007 Porto Alegre, RS, Brazil \\ ${ }^{2}$ Universidade Federal do Rio Grande do Sul, Instituto de Física, \\ Av. Bento Gonçalves, 9500, 91501-970 Porto Alegre, RS, Brazil
}

Manuscript received on September 14, 2016; accepted for publication on March 17, 2017

\begin{abstract}
This article presents an analysis of Brazilian research on High Energy Physics (HEP) indexed by Web of Science (WoS) from 1983 to 2013. Scientometric indicators for output, collaboration and impact were used to characterize the field under study. The results show that the Brazilian articles account for $3 \%$ of total HEP research worldwide and that the sharp rise in the scientific activity between 2009 and 2013 may have resulted from the consolidation of graduate programs, the increase of the funding and of the international collaboration as well as the implementation of the Rede Nacional de Física de Altas Energias (RENAFAE) in 2008. Our results also indicate that the collaboration patterns in terms of the authors, the institutions and the countries confirm the presence of Brazil in multinational Big Science experiments, which may also explain the prevalence of foreign citing documents (all types), emphasizing the international prestige and visibility of the output of Brazilian scientists. We concluded that the scientometric indicators suggested scientific maturity in the Brazilian HEP community due to its long history of experimental research.
\end{abstract}

Key words: Brazil, High Energy Physics, impact, scientific collaboration, scientific output, scientometrics.

\section{INTRODUCTION}

High Energy Physics (HEP) is considered one of the most internationalized and collaborative scientific knowledge areas (Mele et al. 2006). Since the 1950s, large experiments with particle accelerators have involved scientists from several countries. The small number of laboratories, operational costs of research and interdisciplinarity are factors that

Correspondence to: Samile Andréa de Souza Vanz

E-mail: samilevanz@terra.com.br strengthen ties between nations. The prevalence of multiauthor publications on HEP is the result of a strong culture of communication and scientific exchange.

This collective effort generates information on particle interaction and the formation of the universe, in addition to knowledge transferred to areas such as Medicine (the development of CT scans and radiation therapy for cancer diagnosis and treatment), Information \& Communication Technology (creation of the World Wide Web), 
Engineering (improving the quality of thermal insulation for electrical equipment), the Environment (renewable energy production) (Santoro and Novaes 2003, Lefevre 2007).

In 2008, Brazil began to work towards becoming an Associate Member of the European Organization for Nuclear Research (CERN). Despite not being formally affiliated with the institution, collaboration by Brazilian HEP is significant and long-standing. In terms of number of researchers, students and engineers, Brazil has the second largest participation among non-member countries, second only to Canada. Concomitantly, Brazilian researchers in the field participate in major international projects in partnership with National Laboratories such as the Fermi National Accelerator Laboratory (Fermilab) and Brookhaven National Laboratory (BNL) in the United States, and Pierre Auger in Argentina (Coordernação de Aperfeiçoamento de Pessoal de Nível Superior/ CAPES 2013).

It is known that joining CERN alone is not enough to ensure a quality leap in HEP research in Brazil; significant investment in infrastructure, the creation of new laboratories and training of human resources are also needed (Lépine-Szily et al. 2011). It should be noted that no specific scientometric study on Brazilian HEP was found in the existing literature. Therefore, this article identifies the peculiarities of research in the field, national and international co-participation, and research visibility through citations. Moreover, it can be used as a source of information for decisionmaking in relation to granting new funding and graduate scholarships.

This article presents an analysis of the characteristics of the scientific output, the collaboration and impact of Brazilian HEP. The analysis is based on articles published in journals indexed under the Web of Science Category (WC) 'Physics, Particles \& Fields' between 1983 and 2013.

\section{OVERVIEW OF HEP RESEARCH IN BRAZIL}

Research on high-energy cosmic rays in Brazilian HEP and collaboration between scientists have been systematic since the 1930s, especially with the creation of the first universities in São Paulo and Rio de Janeiro and the arrival of foreign physicists, including the Italian Gleb Wataghin and the German Bernard Gross (Schwartzman 2001, Motoyama 2004). The participation of César Lattes in the discovery of meson $\pi$ in 1947 and the creation of the physics research center, Centro Brasileiro de Pesquisas Físicas (CBPF), in 1949, contributed to the consolidation of HEP as a thematic area of research. The establishment of the two governamental grant agencies, Conselho Nacional de Desenvolvimento Científico e Tecnológico (CNPq) and CAPES, in 1951, boosted the development of national science and of Physics in particular. The creation of federal and state universities in the 1960s (and more intensely in subsequent decades) propelled the development of human resources. The high education system consolidated and in the second half of the 1960s, graduate programs were established in the country (Sociedade Brasileira de Física/SBPF 1987, Schwartzman 2001, Vieira and Videira 2007, Shellard 2011). The first program with an HEP research line was offered by the CBPF in 1962 (Sistema Nacional de Pós-Graduação/ SNPG 2015). The most recent assessment of graduate programs conducted by CAPES revealed the rapid development of teaching in the area. Among the 32 graduate HEP programs graded in the Avaliação Trienal, 11 were regarded as having an international profile and deemed outstanding, receiving the highest grades (CAPES 2013).

The participation in the large collaborations in HEPrequires specific planning related not only to the visits to the international laboratories but also to the selection of experiments in which the scientists from Brazil can participate. Then, in 2008, the Ministério de Ciência e Tecnologia (MCT) set up the Rede 
Nacional de Física de Altas Energias (RENAFAE). Its main objectives are to study particles and their interactions, coordinate activities related to major international collaborations and devise a project for the development of instrumentation and software (CBPF 2011, Shellard 2011). In the scientific community, the creation of RENAFAE is believed to be responsible for a major boost in HEP research in Brazil, given that the number of publications and research groups registered in the $\mathrm{CNPq}$ directory have since increased considerably. While the rise in the number of graduate programs has been less pronounced, consolidation and expansion of programs with HEP research lines are thought to have occurred. According to the CBPF (2011), RENAFAE has played a key role in the articulation of Brazilian collaborations in international projects, including experiments conducted at CERN and the Pierre Auger Observatory.

\section{SCIENTOMETRIC STUDIES ON HEP}

Previous studies by national and international researchers analyzed different aspects of HEP scientific output, collaborations and impact. Although HEP is the focus of analysis in foreign research, studies in Brazil provide an indirect overview of the field, such as the investigations by Vanz (2009), who observed the formation of large groups (teamwork) in the field due to the high cost of research and the complexity of experiments; and Duarte (2008), who stated that scientific and technological development in HEP should be based on international collaboration and Brazilian participation in CERN.

A number of international studies also stand out. Braun et al. (1992) compared the patterns of international co-authorship in the subfields of physics, underscoring, in HEP, the role of multinational laboratories in building partnerships. These studies highlight the similarities and differences between HEP and other collaborative associations. For instance, Kretschmer and Rousseau (2001) found that, in fields such as HEP, Lotka's law is annulled by intense collaboration. Also, Chompalov et al. (2002) reported 53 multiinstitutional collaborations in Physics, observing that HEP is more participatory and consensual in terms of decision-making. Complementary to Chompalov et al. (2002), Newman (2001a, b, c, 2004) examined the structure of scientific collaboration networks in different fields and noted that HEP exhibits a high level of clustering. Krause et al. (2007) studied the geographical distribution of authors who published articles in major HEP journals in 2005-2006 and found that the United States and CERN Members States are the most productive and collaborative countries. Lehmann et al. (2003) demonstrated the homogeneous of the HEP citing network consisting of scientific publications indexed in SPIRES database. Likewise, Collazo-Reyes and Luna-Morales (2002) analyzed the scientific output and growth of Mexican HEP between 1971 and 2000, underscoring the maturity of the scientific community at the local level. Bonilla-Calero (2009) found high rates the scientific output, international collaboration and impact of Spanish HEP from articles indexed in the Science Citation Index (SCI) and arXiv between 2000 and 2005. Mele et al. (2006) considered the HEP preprints submitted in 2005 in the arXiv repository and observed that the scientific output later published in peer review journals is highly concentrated in six titles. Corresponding to Mele et al. (2006), Aman (2013) described the scholarly communication system using articles from core HEP journals indexed by Scopus, emphasizing that only three of the six publications centralizes $50 \%$ of HEP literature. Finally, Collazo-Reyes et al. (2004) observed publication and citing patterns in the Mexican Particle Physics community in SPIRES between 1971 and 2000, recognizing the communication models typical of a Big Science field. 


\section{MATERIALS AND METHODS}

In December 2014, data were collected and Brazilian HEP articles for the 1983-2013 period were downloaded from the SCI of the multidisciplinary Web of Science (WoS) database. The Advanced Search option was used, with the use of boolean operators (OR, AND). The field labels $\mathrm{CU}=$ Country (Brazil OR Brazil) and $\mathrm{WC}=\mathrm{Web}$ Category of Science (Physics, Particles \& Fields) were used in the search strategy to demarcate articles published by Brazilian HEP scientists and to delimit the subject category of journals indexed by WoS. After importing 6,350 bibliographic records, the information was organized into a single file (.txt). We used the List of Authorities from the Grupo de Pesquisa Comunicação Científica of the Universidade Federal do Rio Grande do Sul (UFRGS) and the CNPq Plataforma Lattes to standardize the names of authors, institutions and countries. For impact analysis, data from 41,152 citing documents (all types) were imported using the WoS tool Create Citation Report.

The variables analyzed were Published Year (PY), Web of Science Category (WC), Source (SO), Author (AU), Author Address (C1) and Total Times Cited Count (Z9). General and specific scientometric indicators were used to characterize Brazilian HEP. Output Indicators: Total Publication (TP), Growth Rate (GR). Collaboration Indicators: International Collaboration (ICO), National Collaboration (NCO), Not Collaboration (NotC), Average Author Per Publication (AAPP), Average Institution Per Publication (AIPP), Average Country Per Publication (ACOPP). Impact Indicators: Publication Cited (PC), Total Citation (TC), H Index, Maximum Citation (MaxC), Average Citation Per Publication (ACPP). International co-authorship is the percentage of articles with authors from more than one country. With regard to data processing, software programs Bibexcel (descriptive analysis), Pajek (collaboration networks), Philcarto (thematic mapping), SPSS 18.0 (multivariate analysis) and Microsoft Excel 2007 were used. Salton's Cosine was employed as similarity measure to examine the strength of the ties between Brazil and coauthoring countries, using the formula proposed by Luukkonen et al. (1993). The intensity of inter-country collaboration was classified according to criteria adopted by Leta et al. (2006): strong relationship (Salton's Cosine $\geq$ 2.5); medium relationship (Salton's Cosine $\geq 1$ and $<2.5$ ); weak relationship (Salton's Cosine $<1$ ).

The Person correlation measurement was used to analyze if the increase in citations in Brazilian HEP total publication partially resulted from the growth of international collaborations:

$$
r=\frac{\sum\left(x_{i}-(x)\left(y_{i}-(y)\right.\right.}{\sqrt{\sum\left(x_{i}-(x)\right)^{2}} \sqrt{\sum\left(y_{i}-\left(y()^{2}\right.\right.}}
$$

where $x_{i}$ and $y_{i}$ are the measures of total number of citations and total number of publications in international collaborations in each year and $<\mathrm{x}>$ and $<y>$ are the average number along the period.

The thirty-one-year period studied (19832013) was aimed at ensuring greater reliability of scientometric indicators by using an extensive time period to analyze the evolution of scientific production in Brazilian HEP. In line with the strategy used by other researchers, such as Kretschmer and Rousseau (2001), Vanz (2009) and Bonilla-Calero (2009), this study employed total counts, that is, an entire article or citation for each author, institution or country.

\section{RESULTS AND DISCUSSION}

\section{CHARACTERIZATION OF BRAZILIAN HEP RESEARCH}

The Brazilian HEP contribution to the global output indexed in the WoS WC (Advanced Search) 
Physics, Particles \& Fields for the 1983-2013 period was analyzed and compared with other countries. Brazilian HEP articles accounted for 3\% of the total investigated. The Brazilian participation in HEP is more representative when compared to the participation of Brazil in the total production indexed in SCI $(1.72 \%)$. The most productive country in HEP is the United States $(29.78 \%)$, followed by Germany (13.60\%), Italy $(11.77 \%)$, the United Kingdom (9.10\%) and Russia (8.96\%). Brazil occupies the fourteenth position in terms of participation. In order to identify if this position can potentially change in the next years, the growth of Brazilian and international publications was examined. Fig. 1 shows the Brazilian growth (right vertical axis) with the total global production (left vertical axis). While the global production shows an inverse parabolic growth $\left(\mathrm{R}^{2}=0.979\right)$, the Brazilian production increases much faster by an exponential growth $\left(\mathrm{R}^{2}=0.9131\right)$.

Our results show that the average publications growth in this period in Brazil, $14.27 \%$, is larger than that of world publications, $3.78 \%$. Since we analyze a more recent period of time, the average recorded here is higher than the $10.7 \%$ reported by Almeida and Guimarães (2013) for Brazilian scientific output from 1980 to 2010 period, the $6.4 \%$ found by Bonilla-Calero (2009) for Spanish Particle Physics output indexed in the SCI between 2000 and 2005, and the $12.5 \%$ observed by Vanz (2009) for Brazilian Physics articles published between 2004 and 2006. This recent exceptional growth, between 2009 and 2013, coincides with the establishment of RENAFAE. It is important to note that the increase in the number of national journals indexed in WoS from 2007 to 2008 and the resulting rise in Brazilian scientific production (Leta 2012, Vargas et al. 2014) did not affect HEP, since a negative growth rate was observed in $2008(-18.91 \%)$. The analysis of the journals of publication presented later confirms the independence of the Brazilian HEP for the national communication vehicles. The creation of new $\mathrm{CNPq}$ research groups, the consolidation and expansion of graduate programs, greater financial resources and the key coordinating role of RENAFAE for Brazilian collaboration in international experiments may have been determining factors for the increase in the volume of articles in these years and, consequently, development in the field.

The Table I illustrates the year-on-year output, collaboration and impact data. The table shows for each year: the total number of publications (TP), the percentual growth rate between the number of publications in one year compared with the number in the previous year (GR), the percentual of publications in international collaboration (ICO), the percentual of publications in national collaboration (NCO), the percentual of publications without collaboration (NotC), the percentual of publications that received any citation (PC), the total number of citations (TC), the average number of citations per publication (ACPP).

A significant difference was observed in the number of published articles in the study period. In 1983, WoS indexed journals published only 25 articles by Brazilian researchers. In 2013, output reached its peak at 577 publications. A significant increase in scientific activity of Brazilian HEP was seen over the period and can be associated to the presence and growth of the collaboration in the Brazilian HEP articles. In the case of TP and ICO $r=0.97$ and $\mathrm{TP}$ and $\mathrm{NCO} r=0,91$, which suggests strong correlation.

Brazilian HEP scientific output indexed in WoS from 1983 to 2013 amounts to 6,350 articles, accounting for an average of 205 publications per year. The set of Brazilian HEP articles studied received 78,812 citations from 41,152 documents (all types), representing an average of 12.41 citations per article. In terms of visibility, significant internationalization of research in the field seems to have contributed to the high rate of articles with at least one citation (87.65\%). According to Lehmann 


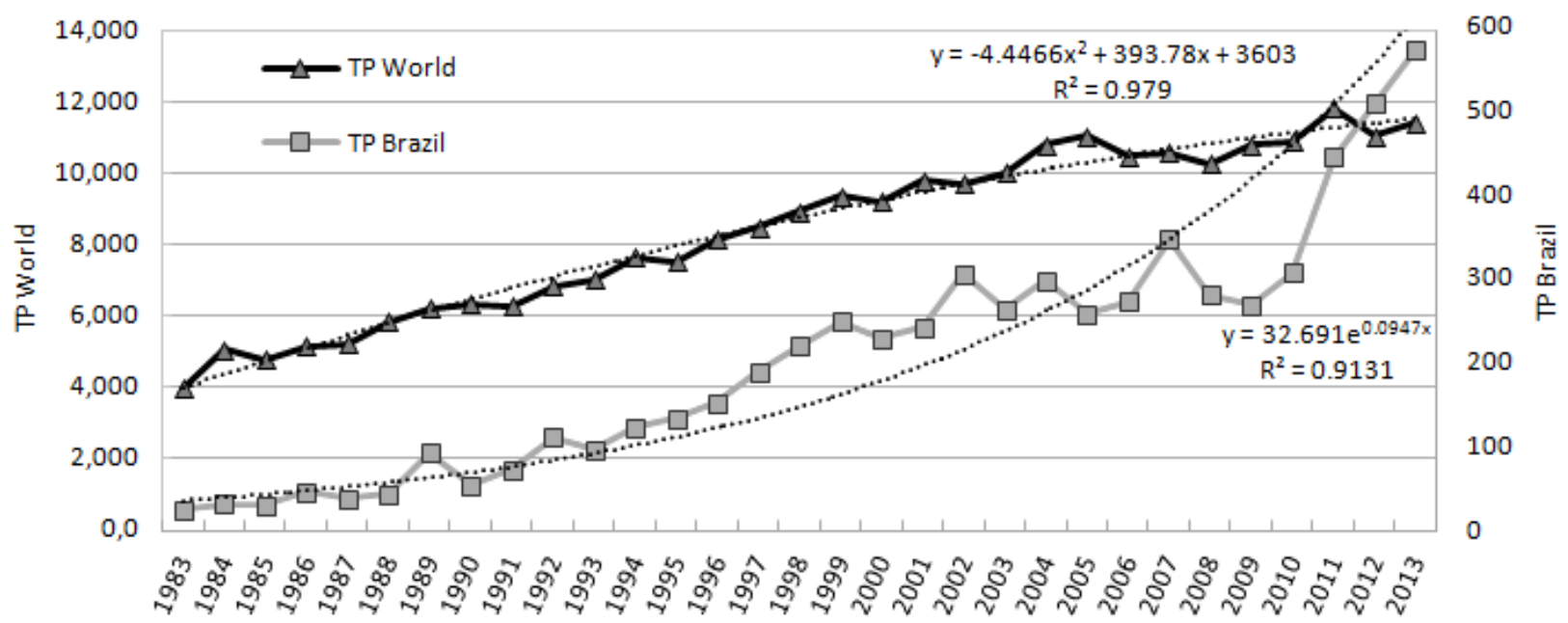

Figure 1 - Growth dynamics of Brazilian and international HEP publications, 1983-2013. The right vertical axis is for the TP Brazil and the left vertical axis for the TP World.

TABLE I

Annual evolution of Brazilian HEP scientific activity, 1983-2013.

\begin{tabular}{|c|c|c|c|c|c|c|c|c|}
\hline \multirow{2}{*}{ Year } & \multicolumn{2}{|c|}{ Output } & \multicolumn{3}{|c|}{$\%$ Collaboration ${ }^{a}$} & \multicolumn{3}{|c|}{ Impact } \\
\hline & TP & GR (\%) & ICO & NCO & NotC & PC (\%) & TC & ACPP \\
\hline 1983 & 25 &.. & 22.22 & 0.00 & 77.78 & 92.00 & 598 & 23.92 \\
\hline 1984 & 32 & 28.00 & 13.33 & 20.00 & 66.67 & 84.38 & 382 & 11.93 \\
\hline 1985 & 30 & -6.25 & 18.75 & 18.75 & 62.50 & 96.67 & 279 & 9.30 \\
\hline 1986 & 47 & 56.66 & 37.50 & 12.50 & 50.00 & 91.49 & 466 & 9.91 \\
\hline 1987 & 39 & -17.02 & 27.27 & 9.10 & 63.63 & 89.74 & 336 & 8.61 \\
\hline 1988 & 44 & 12.82 & 47.37 & 5.26 & 47.37 & 95.45 & 858 & 19.50 \\
\hline 1989 & 93 & 111.36 & 26.53 & 10.20 & 63.27 & 87.10 & 679 & 7.30 \\
\hline 1990 & 54 & -41.93 & 37.93 & 24.14 & 37.93 & 81.48 & 791 & 14.64 \\
\hline 1991 & 73 & 35.18 & 37.78 & 2.22 & 60.00 & 82.19 & 863 & 11.82 \\
\hline 1992 & 112 & 53.42 & 53.73 & 2.99 & 43.28 & 87.50 & 2,194 & 19.58 \\
\hline 1993 & 97 & -13.39 & 31.67 & 6.67 & 61.67 & 90.72 & 1,744 & 17.97 \\
\hline 1994 & 123 & 26.80 & 45.35 & 10.47 & 44.19 & 82.93 & 1,499 & 12.18 \\
\hline 1995 & 135 & 9.75 & 52.43 & 8.74 & 38.83 & 86.67 & 2,054 & 15.21 \\
\hline 1996 & 153 & 13.33 & 48.54 & 9.71 & 41.75 & 92.16 & 2,891 & 18.89 \\
\hline 1997 & 190 & 24.18 & 43.38 & 6.62 & 50.00 & 92.11 & 2,511 & 13.21 \\
\hline 1998 & 221 & 16.31 & 54.75 & 13.12 & 32.13 & 89.59 & 3,072 & 13.90 \\
\hline 1999 & 251 & 13.57 & 45.02 & 17.53 & 37.45 & 88.05 & 3,077 & 12.25 \\
\hline 2000 & 231 & -7.96 & 47.19 & 21.21 & 31.60 & 90.48 & 4,017 & 17.38 \\
\hline 2001 & 244 & 5.62 & 46.72 & 17.21 & 36.07 & 90.57 & 3,587 & 14.70 \\
\hline 2002 & 308 & 26.22 & 44.16 & 19.48 & 36.36 & 88.64 & 4,220 & 13.70 \\
\hline 2003 & 265 & -13.96 & 45.28 & 24.53 & 30.19 & 90.19 & 4,496 & 16.96 \\
\hline 2004 & 300 & 13.20 & 38.33 & 25.67 & 36.00 & 85.00 & 4,978 & 16.59 \\
\hline 2005 & 260 & -13.33 & 45.00 & 24.62 & 30.38 & 86.15 & 3,542 & 13.62 \\
\hline
\end{tabular}


TABLE I (continuation)

\begin{tabular}{|c|c|c|c|c|c|c|c|c|}
\hline \multirow{2}{*}{ Year } & \multicolumn{2}{|c|}{ Output } & \multicolumn{3}{|c|}{$\%$ Collaboration ${ }^{a}$} & \multicolumn{3}{|c|}{ Impact } \\
\hline & TP & GR (\%) & ICO & NCO & NotC & PC (\%) & TC & ACPP \\
\hline 2006 & 274 & 5.38 & 44.89 & 22.99 & 32.12 & 88.69 & 4,222 & 15.40 \\
\hline 2007 & 349 & 27.37 & 37.82 & 26.65 & 35.53 & 84.53 & 3,983 & 11.41 \\
\hline 2008 & 283 & -18.91 & 40.28 & 28.62 & 31.10 & 94.35 & 4,021 & 14.20 \\
\hline 2009 & 271 & -4.24 & 45.02 & 23.25 & 31.73 & 88.93 & 2,978 & 10.98 \\
\hline 2010 & 309 & 14.02 & 46.93 & 22.98 & 30.10 & 90.94 & 4,062 & 13.14 \\
\hline 2011 & 448 & 44.98 & 57.14 & 20.54 & 22.32 & 85.49 & 4,246 & 9.47 \\
\hline 2012 & 512 & 14.28 & 65.23 & 17.19 & 17.58 & 90.82 & 4,136 & 8.07 \\
\hline 2013 & 577 & 12.69 & 67.24 & 14.04 & 18.72 & 77.30 & 2,030 & 3.51 \\
\hline .. & 6,350 & 14.27 & 49.07 & 19.19 & 31.74 & 87.65 & 78,812 & 12.41 \\
\hline
\end{tabular}

TP total publication, GR growth rate, ICO international collaboration, NCO national collaboration, NotC not collaboration, PC publication cited, TC total citation, ACPP average citation per publication. ${ }^{a}$ Within the 6,350 articles analyzed, 5,886 (92.70\%) contained information in the $\mathrm{C} 1$ field in WoS. The 464 articles with no information in field C1 correspond to the period $1983-1997$. Therefore, TP has a higher value than the sum of ICO, NCO and NotC in that interval.

et al. (2003), a smaller number of minimally cited HEP articles would be expected, due to the operational cost of experiments, strict research controls and the large number of co-authors.

It is interesting to notice that the most cited article (484 citations), 'Properties and performance of the prototype instrument for the Pierre Auger Observatory', it was not for an experiment at CERN, but for building up an instrument for the detection and study of cosmic rays in a large apparatus built in Argentina. The article was published in 2004 by the Auger Collaboration in the journal Nucl. Instrum. Meth. A. This particular project was very important to Brazil because due to the location of the instruments, the technical support largely came from Brazilian companies.

Then we analyzed if the increase in citations in Brazilian HEP total publication partially resulted from the growth of international collaborations. Fig. 2 shows the number of articles in international collaboration (ICO) at the left vertical axis and the total number of citations (TC) at the right vertical axis from 1983 up to 2013. Although the number of citations decreased in 2012-2013 because articles published in this period have not yet been incorporated by the scientific community and referenced in further studies (Meadows 1999), the expansion of International Collaboration contributed in some measure to the increased visibility of research by Brazilian scientists. In the Fig. 2 both the total number of citations and the number of articles in international collaborations are moderately correlated. Systems that show low correlation have $r$ close to zero while systems in which the correlation is high the value is close to 1. In the case of TC and ICO $\mathrm{r}=0.62$ what suggests moderate correlation.

Brazilian HEP articles were analyzed by theme using the WC field in order to determine the distribution of publications per subject for the journals used and relate this to patterns of collaboration and citations received. The Table II shows for each theme in the high energy physics the total number of publications, the percentage of the total number of publications, the average number of authors per publication, the average number of institutions per publication, the average number of countries per publication, the total number of citations, the average number of citations per publication in each specified theme of HEP. It 


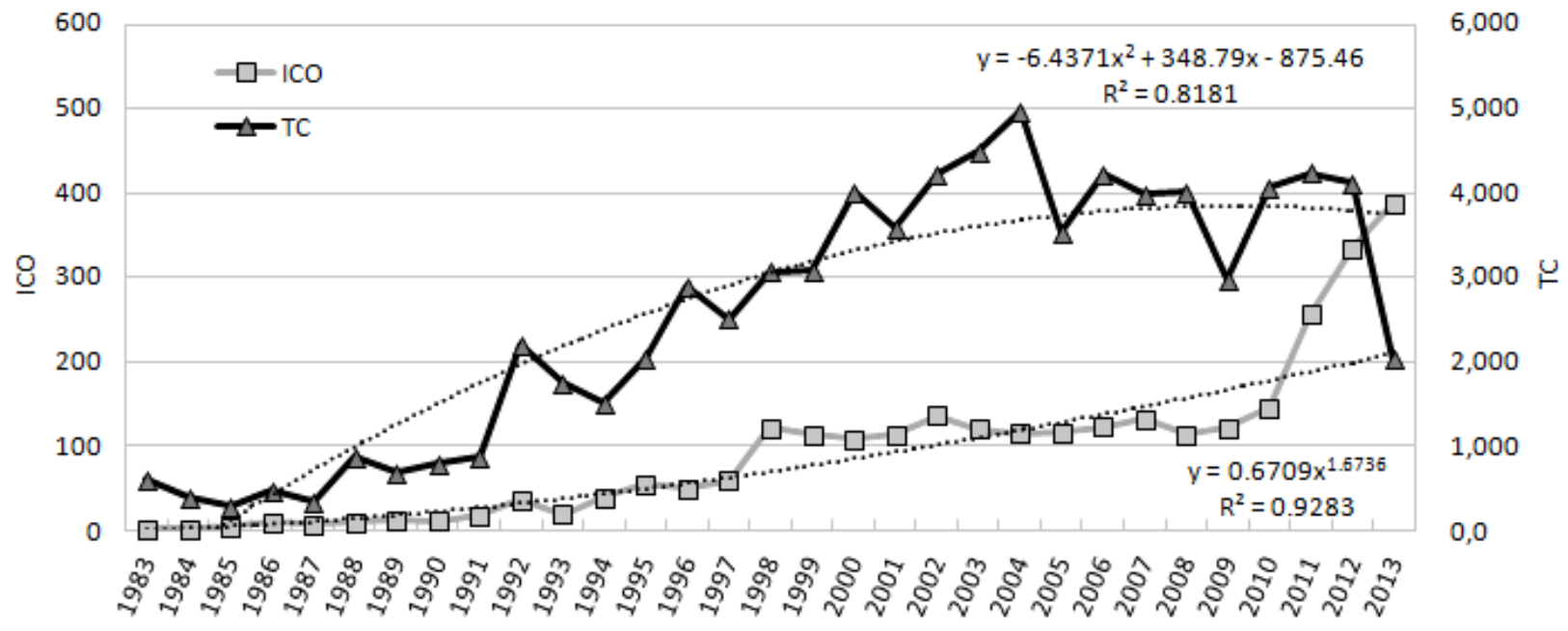

Figure 2 - International collaboration and citation patterns of Brazilian HEP, 1983-2013. The left vertical axis is for the international collaboration (ICO), while the right vertical axis is for the total number of citations (TC).

should be noted that the same document can be classified into more than one category, and as such, the sum of identified occurrences does not match the total number of articles in scientific production.

Despite the multidisciplinarity and complexity of Brazilian HEP research, since Brazilian articles were also indexed by journals for other fields, the distribution publications per $\mathrm{WC}$ in the period covered was low compared with the totality of subject categories of WoS. This indicator shows that the field studied often concentrates research results within a limited number of specialized journals. The concentration of the publications in the theme of Astronomy \& Astrophysics and Nuclear Physics in Brazilian publications stems not only from their significant influence on HEP in the historical context, but also from the interest in subjects such as dark matter, neutrinos, The Big Bang, astroparticles, heavy-ion collisions, reactions on stars, and decays. The highest contribution and impact rates for the period were observed in the most productive $\mathrm{WC}$ and in technical areas strongly linked to detection methods and control of nuclear reactions (Nuclear Science \& Technology), detectors and accelerators (Instruments \& Instrumentation) as well as measurements of quantum numbers of particles (Spectroscopy). With only one article, the WCs Materials Science, Multidisciplinary; Physics, Applied and Physics, Condensed Matter showed low representativeness in the set of articles examined. As such, these three categories showed low AAPP, AIPP, ACOPP and ACPP.

Another aspect is the selection of the journals in which the publications appear. The Table III illustrates for each different journal (the home country of the journal is also specified) the total number of publication, the percentage of the number of publications, the average number of authors per publication, the average number of institutions per publication, the average number of countries per publication, the total number of citations, the $\mathrm{H}$ index, and the average number of citations per publication. The 6,350 Brazilian HEP articles indexed in WoS for the 1983-2013 period are published in 35 international English-language journals. The fact that the first PhDs in Physics and Astronomy were trained abroad is one of the reasons for the preference for English-language journals as a communication channel for research results (CAPES 2013). Among the 15 foreign journals that were most used by researchers, the 
TABLE II

Thematic areas in the scientific output of Brazilian HEP, 1983-2013.

\begin{tabular}{|c|c|c|c|c|c|c|c|}
\hline \multirow{2}{*}{ Theme } & \multicolumn{2}{|c|}{ Output } & \multicolumn{3}{|c|}{ Collaboration } & \multicolumn{2}{|c|}{ Impact } \\
\hline & TP & $\%$ & AAPP & AIPP & ACOPP & TC & ACPP \\
\hline Astronomy \& Astrophysics & 3,003 & 45.63 & 98.13 & 12.50 & 3.66 & 43,987 & 14.64 \\
\hline Physics, Nuclear & 1,228 & 18.66 & 5.05 & 2.40 & 1.58 & 6,529 & 5.31 \\
\hline Physics, Multidisciplinary & 556 & 8.45 & 4.14 & 2.03 & 1.40 & 5,654 & 10.16 \\
\hline Nuclear Science \& Technology & 442 & 6.72 & 30.12 & 6.82 & 3.14 & 5,654 & 12.79 \\
\hline Instruments \& Instrumentation & 435 & 6.61 & 30.57 & 6.92 & 3.14 & 5,650 & 12.98 \\
\hline Spectroscopy & 435 & 6.61 & 30.57 & 6.92 & 3.14 & 5,650 & 12.98 \\
\hline Physics, Mathematical & 410 & 6.23 & 2.74 & 1.86 & 1.31 & 2,124 & 5.18 \\
\hline Computer Science, Theory \& Methods & 42 & 0.64 & 3 & 1.73 & 1.26 & 214 & 5.09 \\
\hline Meteorology \& Atmospheric Sciences & 7 & 0.11 & 7.42 & 2.85 & 2.42 & 41 & 5.85 \\
\hline Geosciences, Multidisciplinary & 7 & 0.11 & 7.42 & 2.85 & 2.42 & 41 & 5.85 \\
\hline Engineering, Aerospace & 7 & 0.11 & 7.42 & 2.85 & 2.42 & 41 & 5.85 \\
\hline Physics, Fluids \& Plasmas & 6 & 0.09 & 2.33 & 2 & 2 & 0 & 0 \\
\hline Materials Science, Multidisciplinary & 1 & 0.01 & 3 & 3 & 3 & 0 & 0 \\
\hline Physics, Applied & 1 & 0.01 & 3 & 3 & 3 & 0 & 0 \\
\hline Physics, Condensed Matter & 1 & 0.01 & 3 & 3 & 3 & 0 & 0 \\
\hline
\end{tabular}

TP total number of publication, percentage of the publications, AAPP average number of authors per publication, AIPP average number of institutions per publication, ACOPP average number of countries per publication, TC total number of citations, ACPP average number of citations per publication in each specified theme of HEP.

titles published in Europe (Germany, England, the Netherlands, Italy) and in the USA, responsible for publishing $85.20 \%$ of the articles (Table III), stood out. The absence of articles in journals published in Brazil confirms the strong internationalization of the field under study. In addition, Table III shows collaboration and impact indicators generated in order to establish the co-authorship and citation patterns of the publication sources preferred by Brazilian HEP scientists.

In terms of productivity, the importance of the most traditional HEP journals, such as Physical Review D, Journal of High Energy Physics, European Physical Journal C and Nuclear Physics B, was noted. As reported by Bonilla-Calero (2009) and Aman (2013), our results show a high concentration of publications in a few journals with a high Impact Factor in the field of Particle Physics, with $70 \%$ of articles published in six journals.
This is lower than $83 \%$ reported by Mele et al. (2006) for the international HEP scientific output in 2005. The arrangement of articles by quartile revealed that the three most productive journals fall under Q1. The level of excellence achieved by Brazilian HEP is supported by the number of top-rated graduate programs according to the 2013 CAPES Avaliação Trienal. The indicators in Table III show highly varied collaboration and impact patterns among different journals. The highest rates recorded were for the journals J. High Energy Phys. (AAPP, AIPP), Eur. Phys. J. C (ACOPP) and Astropart. Phys. (ACPP). Our results also confirms the correlation between $\mathrm{H}$ index and citations (Hirsch 2005) as proposed by Hirsch.

Even though HEP is built in collaborations, the individuals play a relevant role. The Table IV shows the list of more productive Brazilian authors on HEP including their total number 
TABLE III

Fifteen main journals for Brazilian HEP scientific output, 1983-2013.

\begin{tabular}{lccccccccc}
\hline \multirow{2}{*}{ Journal (country) } & \multicolumn{2}{c}{ Output } & \multicolumn{3}{c}{ Collaboration } & \multicolumn{3}{c}{ Impact } \\
\cline { 2 - 8 } & TP & \% & AAPP & AIPP & ACOPP & TC & H Index & ACPP \\
\hline Phys. Rev. D (USA) & 2,259 & 38.47 & 124.23 & 14.93 & 4.15 & 35,640 & 70 & 15.77 \\
J. High Energy Phys (ITA) & 505 & 8.60 & 694.75 & 56.67 & 12.99 & 6,281 & 39 & 12.41 \\
Eur. Phys. J. C (DEU) & 449 & 7.65 & 619.09 & 56.48 & 13.98 & 6,019 & 34 & 13.40 \\
Nucl. Instr. Meth. A (NLD) & 435 & 7.41 & 30.57 & 6.92 & 3.14 & 5,650 & 34 & 12.98 \\
Int. J. Mod. Phys. A (SIN) & 382 & 6.51 & 2.46 & 1.82 & 1.34 & 1,733 & 19 & 4.53 \\
Mod. Phys. Lett. A (SIN) & 354 & 6.03 & 2.74 & 1.89 & 1.30 & 1,841 & 20 & 5.20 \\
Class. Quantum Grav (GBR) & 342 & 5.82 & 5.30 & 2.23 & 1.45 & 3,485 & 28 & 10.19 \\
Nucl. Phys. B (NLD) & 297 & 5.06 & 51.96 & 6.44 & 2.69 & 6,354 & 42 & 21.53 \\
J. Phys. G (GBR) & 232 & 3.95 & 12.02 & 3.49 & 1.95 & 1,780 & 21 & 7.67 \\
Gen. Relat. Gravit (USA) & 187 & 3.18 & 2.28 & 1.69 & 1.32 & 2,060 & 22 & 11.01 \\
J. Cosmo. Astro. Phys (GBR) & 140 & 2.38 & 27.88 & 6.45 & 2.68 & 1,305 & 17 & 9.32 \\
Int. J. Mod. Phys. E (SIN) & 133 & 2.26 & 4.35 & 2.33 & 1.53 & 317 & 9 & 2.38 \\
Astropart. Phys (NLD) & 67 & 1.14 & 117.26 & 22.19 & 6.04 & 1,455 & 20 & 21.71 \\
Eur. Phys. J. A (DEU) & 66 & 1.12 & 7.92 & 3.92 & 2.50 & 542 & 12 & 8.21 \\
Int. J. Quantum Inf(USA) & 24 & 0.41 & 2.79 & 1.58 & 1.08 & 146 & 7 & 6.08 \\
\hline
\end{tabular}

TP total number of publication, percentage of the number of publications, AAPP average number of authors per publication, AIPP average number of institutions per publication, ACOPP average number of countries per publication, TC total number of citations, $\mathrm{H}$ index, ACPP average number of citations per publication in each different journal with the specified home country of the journal.

of publications, the total number of citations, the number of citations of their articles with the maximum number of citations, the average number of citations per publication. The most productive Brazilian scientist for the period was Maria Elena Pol, a female PhD in Physics from the Pontifícia Universidade Católica of Rio de Janeiro, with 316 articles. She is currently Head Researcher II for CBPF, with experience in the field of experimental HEP and especially in the standard model of electroweak interactions, data processing software, physics of detectors, and particle identification. She is also a member of CERN's Compact Muon Solenoid (CMS) research group.

The 20 most productive Brazilian authors are experimental and they are affiliated to public institutions in the states of Rio de Janeiro and São Paulo: Universidade do Estado do Rio de Janeiro (UERJ), Universidade Federal do Rio de Janeiro
(UFRJ), Universidade Estadual Paulista Júlio de Mesquita Filho (UNESP) and Centro Brasileiro de Pesquisas Físicas (CBPF). The distribution of the number of articles per author between 1983 and 2013 shows that 7,674 (29.87\%) published only one article. The rate obtained is almost 30\% lower than the $60 \%$ predicted by Lotka's inverse square model, as shown in other HEP studies (Kretschmer and Rousseau 2001).

The productivity and impact of the group of scientists were estimated using the H Index. Maria Elena Pol and Marcia Begalli have the highest $\mathrm{H}$ index (39), indicating the visibility and relevance of the scientific production of these researchers in HEP. In terms of individual productivity, the good performance of Brazilian HEP is related to the active participation in CNPq research groups and international collaboration with CERN in Switzerland as well as Fermilab and Brookhaven in 
TABLE IV

Twenty most productive Brazilian HEP authors, 1983-2013.

\begin{tabular}{|c|c|c|c|c|c|}
\hline \multirow{2}{*}{ Author (institution) } & \multirow{2}{*}{$\begin{array}{c}\text { Output } \\
\text { TP }\end{array}$} & \multicolumn{4}{|c|}{ Impact } \\
\hline & & TC & H Index & MaxC & ACPP \\
\hline Pol M. E. (CBPF) & 316 & 6,503 & 39 & 413 & 20.57 \\
\hline Mundim L. (UERJ) & 282 & 5,255 & 34 & 413 & 18.63 \\
\hline Begalli M. (UERJ) & 243 & 6,097 & 39 & 413 & 25.09 \\
\hline Alves G. A. (CBPF) & 241 & 4,808 & 34 & 413 & 19.95 \\
\hline Novaes S. F. (UNESP) & 235 & 4,204 & 33 & 413 & 17.88 \\
\hline Gandelman M. (UFRJ) & 228 & 4,220 & 32 & 317 & 18.59 \\
\hline Carvalho W. (UERJ) & 219 & 4,436 & 33 & 413 & 20.25 \\
\hline Amato S. (UFRJ) & 219 & 4,008 & 32 & 317 & 18.30 \\
\hline Gregores E. M. (UNESP) & 217 & 3,846 & 30 & 413 & 17.72 \\
\hline Santoro A. (UERJ) & 215 & 3,941 & 33 & 413 & 18.33 \\
\hline Mercadante P. G. (UNESP) & 215 & 3,050 & 28 & 153 & 14.18 \\
\hline Sznajder A. (UERJ) & 202 & 3,585 & 29 & 413 & 17.74 \\
\hline de Paula L. (UFRJ) & 177 & 2,466 & 26 & 104 & 13.93 \\
\hline da Silva W. L. P. (UERJ) & 165 & 2,516 & 26 & 413 & 15.24 \\
\hline Nogima H. (UERJ) & 161 & 2,487 & 25 & 484 & 15.44 \\
\hline Lopes J. H. (UFRJ) & 159 & 2,066 & 23 & 104 & 12.99 \\
\hline Oguri V. (UERJ) & 156 & 3,324 & 29 & 413 & 21.30 \\
\hline Rangel M. S. (UFRJ) & 156 & 2,383 & 25 & 153 & 15.27 \\
\hline do Vale M. A. B. (UFRJ) & 151 & 1,852 & 21 & 302 & 12.26 \\
\hline Marechal B. (UFRJ) & 150 & 3,491 & 31 & 317 & 23.27 \\
\hline
\end{tabular}

the United States. As a co-author in the most cited HEP article (484 citations), Hélio Nogima (UERJ) had the highest MaxC, while researchers Marcia Begalli (UERJ) and Bernard Marechal (UFRJ) had the highest ACPP for the period.

Since the HEP is a very cooperative field the analysis of the geographic distribution of the publications is relevant to understand how much the field percolated in the country. The Table $\mathrm{V}$ shows the total number of publications, the percentage of the number of publications, the total number of citations, the average number of citations per publication for the different states in Brazil. The table indicates that the federal and state institutions (predominantly universities) lead the ranking of the most productive institutions in Brazilian HEP. The leading role of institutions from the states of São Paulo and Rio de Janeiro is evident, accounting for almost $76 \%$ of the articles produced. Leta and Cruz (2003) explain that the quantitative differential of graduate students, scientists and organizations involved in the activity and a greater research tradition are among the main factors responsible for the leading position of these states in Brazilian science. On the other hand, the regional concentration of technical and scientific production is a peculiarity of peripheral countries where the decentralization of science is very costly. Although Southeastern states were most cited, the highest ACPP in the period under 
study corresponded to Mato Grosso (Mid-west). Its partnership with institutions in more productive regions may have influenced this result.

In order to understand how the HEP network percolates within each state of Brazil, the productivity of the different institutions was analyzed. The Table VI illustrates the total number of publication, the percentage of the number of publications, the total number of citations, the $\mathrm{H}$ index, the number of citations of the article with maximum number of citations, the average number of citations per publication for the different institutions. Universidade de São Paulo (USP) is the most productive institution in HEP between 1983 and 2013. Its influence on Brazilian science is the result of its focus as a research university and the substantial funding it receives from the state research support agency FAPESP (Leta 2011). USP has the highest $\mathrm{H}$ index (58), highlighting the institution's competence in Brazilian scientific production.

Centro Brasileiro de Pesquisas Físicas holds the second place in the productivity ranking. Since its inception in 1949, the national center has worked in a variety of research fields, including cosmology and relativity, high energy and cosmic rays, nuclear physics and astrophysics, fields and particles, etc. CBPF has carried out several projects in collaboration with universities and national and international research institutes, in addition to participating in a number of HEP projects with the CERN and Fermilab laboratories since 1980. In 2000, the center began effective participation in the Pierre Auger Observatory Project, which involves around 20 countries (CBPF 2011). The highest ACPP corresponds to Pontifícia Universidade Católica do Rio de Janeiro, the only private university among the most productive institutions.

\section{SCIENTIFIC COLLABORATION LEVELS}

In the previous subsection the year by year temporal evolution of the number of publications (Table I), of the distribution in different sub fields (Table II) and of the distribution in different journals (Table III) were presented. Since changes occur in a much larger scale than the year by year an analysis over the decades was performed. Table VII shows the evolution per decade of the 6,350 articles, as well as the average number of authors, institutions and countries per article and the rate of collaboration in Brazilian HEP. This table shows that the strong presence of Brazilian researchers in international collaborations between 2010 and 2013 justified the increase in the averages in this last period and explains the continuous increase in the average number of authors per article. Comparatively, the average of 155.89 authors for the 1983-2013 period is higher than the 8.96 presented by Newman (2001a, b, 2004), the 24.8 reported by Krause et al. (2007) for HEP publications in SPIRES between 1995-1999 and 2005-2006, respectively, and the 62 recorded by Bonilla-Calero (2009) for Spanish Particle Physics articles indexed in SCI between 2000 and 2005 . Only $11.39 \%$ of the articles were written by a single author and $68.26 \%$ presented co-authorship between two or more entities. Based on the share of articles with $\geq 4$ countries $(37.26 \%)$, the existence of large networks was confirmed. Experiments with accelerators and particle detectors require the joint use of facilities, e participation by experts from different areas, and economic contributions from several countries (Bordons and Gómez 2000, Vanz and Stumpf 2010).

Another interesting effect is the correlation between productivity and connectivity. The number of citations is directly correlated with the number of authors and with the number of countries involved in the article (Jones et al. 2008, Ale Ebrahim et al. 2013). This also applies for the HEP in Brazil. The five most productive institutions in Brazilian HEP 
TABLE V

Distribution per state of Brazilian HEP scientific output, 1983-2013.

\begin{tabular}{|c|c|c|c|c|c|}
\hline \multirow{2}{*}{ State } & \multicolumn{2}{|c|}{ Output } & \multicolumn{2}{|c|}{ Impact } & \multirow{2}{*}{ State distribution of TP } \\
\hline & TP & $\%$ & TC & ACPP & \\
\hline São Paulo & 3,616 & 37.89 & 39,537 & 10.93 & \\
\hline Rio de Janeiro & 3,591 & 37.63 & 31,422 & 8.75 & \\
\hline Minas Gerais & 504 & 5.28 & 3,196 & 6.34 & \\
\hline Paraíba & 445 & 4.66 & 4,321 & 9.71 & \\
\hline Rio Grande do Sul & 303 & 3.17 & 1,879 & 6.20 & \\
\hline Espírito Santo & 194 & 2.03 & 1,688 & 8.70 & \\
\hline Distrito Federal & 165 & 1.73 & 2,463 & 14.92 & \\
\hline Bahia & 146 & 1.53 & 2,473 & 16.93 & \\
\hline Paraná & 134 & 1.40 & 1,031 & 7.69 & \\
\hline Rio Grande do Norte & 85 & 0.89 & 1,291 & 15.18 & \\
\hline Ceará & 77 & 0.81 & 482 & 6.25 & \\
\hline Pará & 76 & 0.80 & 492 & 6.47 & \\
\hline Santa Catarina & 61 & 0.64 & 573 & 9.39 & \\
\hline Maranhão & 43 & 0.45 & 593 & 13.79 & \\
\hline Pernambuco & 35 & 0.37 & 231 & 6.60 & \\
\hline Goiás & 14 & 0.15 & 86 & 6.14 & \\
\hline Sergipe & 14 & 0.15 & 54 & 3.85 & \\
\hline Roraima & 11 & 0.12 & 41 & 3.72 & \\
\hline Alagoas & 10 & 0.10 & 79 & 7.90 & \\
\hline Tocantins & 9 & 0.09 & 80 & 8.88 & \\
\hline Amapá & 3 & 0.03 & 5 & 1.66 & \\
\hline Mato Grosso & 3 & 0.03 & 84 & 28.00 & \\
\hline Piauí & 3 & 0.03 & 5 & 1.66 & \\
\hline Acre & 1 & 0.01 & 0 & 0.00 & \\
\hline Mato Grosso do Sul & 1 & 0.01 & 0 & 0.00 & \\
\hline
\end{tabular}

TP total number of publication, percentage of number of publications, TC total number of citations, ACPP average number of citations per publication for the different states in Brazil. The map is in the right panel.

TABLE VI

Twenty most productive institutions in Brazilian HEP, 1983-2013.

\begin{tabular}{lcccccc}
\hline \multirow{2}{*}{ Institution } & \multicolumn{2}{c}{ Output } & & \multicolumn{3}{c}{ Impact } \\
\cline { 2 - 6 } & TP & $\mathbf{\%}$ & TC & H Index & MaxC & ACPP \\
\hline Univ. São Paulo (USP) & 1,436 & 14.96 & 19,697 & 58 & 484 & 13.71 \\
Centro Brasileiro de Pesquisas Físicas (CBPF) & 1,165 & 12.13 & 18,395 & 55 & 484 & 15.78 \\
Univ. Est. Paulista Júlio de Mesquita Filho (UNESP) & 944 & 9.83 & 13,997 & 51 & 413 & 14.82 \\
Univ. Fed. Rio de Janeiro (UFRJ) & 908 & 9.46 & 13,082 & 49 & 317 & 14.40 \\
Univ. Estado Rio de Janeiro (UERJ) & 707 & 7.36 & 11,244 & 44 & 413 & 15.90 \\
Univ. Estadual Campinas (UNICAMP) & 491 & 5.11 & 7,707 & 43 & 484 & 15.69 \\
Univ. Fed. Paraíba (UFPB) & 366 & 3.81 & 4,142 & 31 & 151 & 11.31 \\
\hline
\end{tabular}


TABLE VI (continuation)

\begin{tabular}{lcccccc}
\hline \multirow{1}{*}{\multicolumn{1}{c}{ Institution }} & \multicolumn{2}{c}{ Output } & \multicolumn{3}{c}{ Impact } \\
\cline { 2 - 7 } & TP & $\mathbf{\%}$ & TC & H Index & MaxC & ACPP \\
\hline Univ. Fed. ABC (UFABC) & 361 & 3.76 & 5,211 & 32 & 261 & 14.43 \\
Pontifícia Univ. Católica Rio de Janeiro (PUC-Rio) & 283 & 2.95 & 5,917 & 39 & 317 & 20.90 \\
Univ. Fed. Juiz de Fora (UFJF) & 227 & 2.36 & 2,028 & 22 & 86 & 8.93 \\
Univ. Fed. Fluminense (UFF) & 166 & 1.73 & 2,331 & 21 & 484 & 14.04 \\
Univ. Fed. Espírito Santo (UFES) & 158 & 1.65 & 1,694 & 23 & 71 & 10.72 \\
Univ. Fed. Rio Grande Sul (UFRGS) & 148 & 1.54 & 1,253 & 19 & 79 & 8.46 \\
Univ. Fed. São João del-Rei (UFSJ) & 127 & 1.32 & 1,010 & 15 & 51 & 7.95 \\
Centro Nacional de Energia Nuclear (CNEN) & 111 & 1.16 & 570 & 12 & 45 & 5.13 \\
Univ. Brasília (UnB) & 108 & 1.12 & 955 & 16 & 85 & 8.84 \\
Instituto Nacional de Pesquisas Espaciais (INPE) & 92 & 0.96 & 308 & 11 & 42 & 7.33 \\
Centro Técnico Aeroespacial (CTA) & 90 & 0.94 & 1,111 & 18 & 125 & 12.34 \\
Observatório Nacional (ON) & 81 & 0.84 & 1,251 & 19 & 109 & 15.44 \\
Univ. Fed. Rio Grande Norte (UFRN) & 77 & 0.80 & 1,277 & 19 & 116 & 16.58 \\
\hline
\end{tabular}

TP total number of publication, percentage of the number of publications, TC total number of citations, $\mathrm{H}$ index, MaxC maximum number of citations, ACPP average number of citations per publication for the different institutions.

are also the most connected in the inter-institutional collaborative network. The level of clustering demonstrates the significant concentration of research within a small number of institutions, most notably universities. With regard to coauthorship, the presence of specialized centers with a tradition in Nuclear Physics and High Energy Physics is noted, such as Centre National de la Recherche Scientifique (CNRS) and Commissariat à L'énergie Atomique (CEA) in France, Istituto Nazionale di Fisica Nucleare (INFN) in Italy, and the Joint Institute for Nuclear Research (JINR) and Institute for High Energy Physics (IHEP) in Russia. The role of American (Fermilab) and European (CERN) experimental laboratories in establishing institutional partnerships is clear, as is the importance of INFN in terms of funding and productivity (Mele et al. 2006, Adams and King 2009). The predominance of foreign institutions in the network confirms the internationalization of research and Brazil's presence in the multinational groups DØ (Fermilab), CMS and DELPHI (CERN).
The international collaborative network for Brazilian HEP displays strength as to its structure. Absolute indicators show that the United States $(6.10 \%)$ is Brazil's main partner in terms of coauthoring for the 1983-2013 period, followed by Russia (4.56\%), and CERN Member States with a long history in experimental research: France (4.34\%), Germany (4.32\%), UK (4.19\%), and Italy $(4.18 \%)$. The low presence of the USA in HEP articles implies a decline in Brazil's scientific dependence and the consolidation of ties with other partners, mostly in Europe.

Relative indicators show that neighboring Colombia (20.6) is Brazil's main co-author (Table VIII). Geographical proximity encourages the establishment of partnerships (Katz 1994), especially in a country as Brazil, where geographical distance is a decisive factor in collaboration (Sidone et al. 2017). In the field of HEP, the analysis of collaborative strength indicates decentralization and diversification for Brazil's collaborations, with a strong presence of East European countries 
TABLE VII

Summary of the main collaboration results for Brazilian HEP, 1983-2013.

\begin{tabular}{cccccccc}
\hline \multirow{2}{*}{ Period } & \multicolumn{3}{c}{ Average Per Publication } & \multicolumn{4}{c}{ \% Collaboration } \\
\cline { 2 - 7 } & Authors & Institutions & Countries & Authors & Institutions & International \\
\hline $1983-1992$ & 9.55 & 3.74 & 2.29 & 85.79 & 45.76 & 36.61 \\
$1993-2002$ & 36.49 & 6.38 & 2.98 & 86.53 & 61.90 & 46.70 \\
$2003-2013$ & 237.37 & 22.91 & 5.92 & 90.07 & 72.87 & 51.00 \\
1983-2013 & $\mathbf{1 5 5 . 8 9}$ & $\mathbf{1 7 . 0 5}$ & $\mathbf{4 . 8 7}$ & $\mathbf{8 8 . 6 1}$ & $\mathbf{6 8 . 2 6}$ & $\mathbf{4 9 . 0 7}$ \\
\hline
\end{tabular}

such as the Czech Republic (16.7), Serbia (16.1), Georgia (14.8) and Belarus (13.8).

\section{ORIGIN OF CITING DOCUMENTS}

Results of the impact ofHEP research were presented and discussed in previous analyses, and citations were characterized in relation to time evolution (Table I), the fields (Table II), the publishing journals (Table III), the author productivity (Table IV) and the institution productivity (Table V, Table VI). Within the 41,152 citing documents (all types) analyzed, 39,555 (96.11\%) contained information in the $\mathrm{C} 1$ field in WoS (Table IX). The number of international citing articles for Brazilian HEP production was $34,721(87.78 \%)$. Citations from documents (all types) produced by authors affiliated with foreign institutions, including studies in collaboration with Brazil, are considered international. On the other hand, national citations correspond to publications produced exclusively by researchers affiliated with Brazilian institutions. Among the international documents (all types), $30,327(76.67 \%)$ originate from documents published by foreign authors, while 4,394 (11.11\%) are from documents produced through foreign collaboration with Brazil. In addition, national HEP scientists accounted for 4,834 (12.22\%) citing documents (all types) published in the 1983-2015 period. The high number of researchers affiliated with foreign institutions in citing documents (all types) underscores the internationalization of research and low self-citation in the field under study.
Fig. 3 shows the global influence of Brazilian HEP research. Brazil's main partners (and the most productive ones in High Energy Physics) between 1983 and 2013 also lead the ranking of citing countries. The United States tops the list of 112 citing nations, with $10.25 \%$ of the documents (all types) published, followed by CERN Member States such as Germany (6.14\%), Italy (4.99\%), and UK (4.45\%).

\section{CONCLUSIONS}

The contribution of Brazilian HEP to global output indexed in the WoS WC Physics, Particles $\&$ Fields from 1983-2013 accounts for 3\% of the total investigated. The national average annual growth rate for publications is higher than the global average, but more inconsistent, with a sharp increase in domestic production between 2009 and 2013. The creation of new CNPq groups, the consolidation of graduate programs, the establishment of RENAFAE, and increased funding and international collaborations may have been key factors in this growth in these years, as well as development in the field. Astronomy \& Astrophysics and Physics, Nuclear are the most representative fields in Brazilian articles. This suggests that having the infrastructure of graduate programs and regular funding through RENAFAE might be the ingredient for the growth.

The most productive authors are affiliated with institutions in the Rio de Janeiro-São Paulo axis and belong to the experimental subfield. The 
TABLE VIII

Main countries collaborating with Brazil in HEP, 1983-2013.

\begin{tabular}{|c|c|c|c|c|c|}
\hline \multirow{2}{*}{ Country } & \multicolumn{2}{|c|}{ Absolute indicators } & \multirow{2}{*}{ Country } & \multicolumn{2}{|c|}{ Relative indicators } \\
\hline & TP & Share $(\%)$ & & $\mathbf{T P}$ & Salton Cosine \\
\hline USA & 1,399 & 6.10 & Colombia & 441 & 20.6 \\
\hline Russia & 1,042 & 4.56 & Czech Rep. & 635 & 16.7 \\
\hline France & 994 & 4.34 & Serbia & 294 & 16.1 \\
\hline Germany & 991 & 4.32 & Georgia & 304 & 14.8 \\
\hline United Kingdom & 961 & 4.19 & Belarus & 295 & 13.8 \\
\hline Italy & 959 & 4.18 & Portugal & 565 & 13.6 \\
\hline Spain & 818 & 3.57 & Ecuador & 117 & 13.2 \\
\hline Poland & 704 & 3.07 & Armenia & 361 & 12.9 \\
\hline Switzerland & 693 & 3.02 & Slovenia & 327 & 12.4 \\
\hline China & 660 & 2.88 & Greece & 508 & 11.5 \\
\hline Czech Rep. & 635 & 2.77 & Lithuania & 142 & 11.5 \\
\hline Netherlands & 623 & 2.72 & Poland & 704 & 11.1 \\
\hline Portugal & 565 & 2.47 & Austria & 460 & 10.9 \\
\hline Greece & 508 & 2.22 & Romania & 347 & 10.9 \\
\hline Sweden & 482 & 2.10 & Netherlands & 623 & 10.6 \\
\hline Austria & 460 & 2.01 & Estonia & 141 & 10.4 \\
\hline Colombia & 441 & 1.92 & Mexico & 424 & 10.2 \\
\hline Mexico & 424 & 1.85 & Spain & 818 & 10.2 \\
\hline India & 420 & 1.83 & Norway & 325 & 10.1 \\
\hline Belgium & 391 & 1.71 & Argentina & 346 & 20.6 \\
\hline
\end{tabular}

TP total number of publication.

TABLE IX

Summary of the main results for Brazilian HEP citations, 1983-2013.

\begin{tabular}{ccccccc}
\hline \multirow{2}{*}{ Period } & \multicolumn{9}{c}{ Citing documents (all types) } \\
\cline { 2 - 7 } & Nat & \% & Nat\&Int & \% & Int & \% \\
\hline $1983-1993$ & 117 & 14.63 & 99 & 12.38 & 584 & 73.00 \\
$1994-2004$ & 1,660 & 15.44 & 1,290 & 12.00 & 7,801 & 72.56 \\
$2005-2015$ & 3,057 & 10.92 & 3,005 & 10.73 & 21,942 & 78.35 \\
$\mathbf{1 9 8 3 - 2 0 1 5}$ & $\mathbf{4 , 8 3 4}$ & $\mathbf{1 2 . 2 2}$ & $\mathbf{4 , 3 9 4}$ & $\mathbf{1 1 . 1 1}$ & $\mathbf{3 0 , 3 2 7}$ & $\mathbf{7 6 . 6 7}$ \\
\hline
\end{tabular}

Nat National, Nat\&Int National and International, Int International.

data show a concentration of scientific activity in public institutions (predominantly universities). USP, Brazil's largest university, leads the ranking in terms of productivity and citations received. The theoretical subfield stood out for articles written by a single author. This result indicates that the growth in science was driven by the infrastructure and money since both regions in addition to the
RENAFAE funds also have strong financial support from their state.

Scientists' preference for publishing in English-language foreign journals, associated with collaboration patterns in terms of authors, institutions and countries, indicated the presence of Brazil in multinational Big Science experiments and the internationalization of Brazilian HEP. Absolute indicators demonstrate that the USA, 


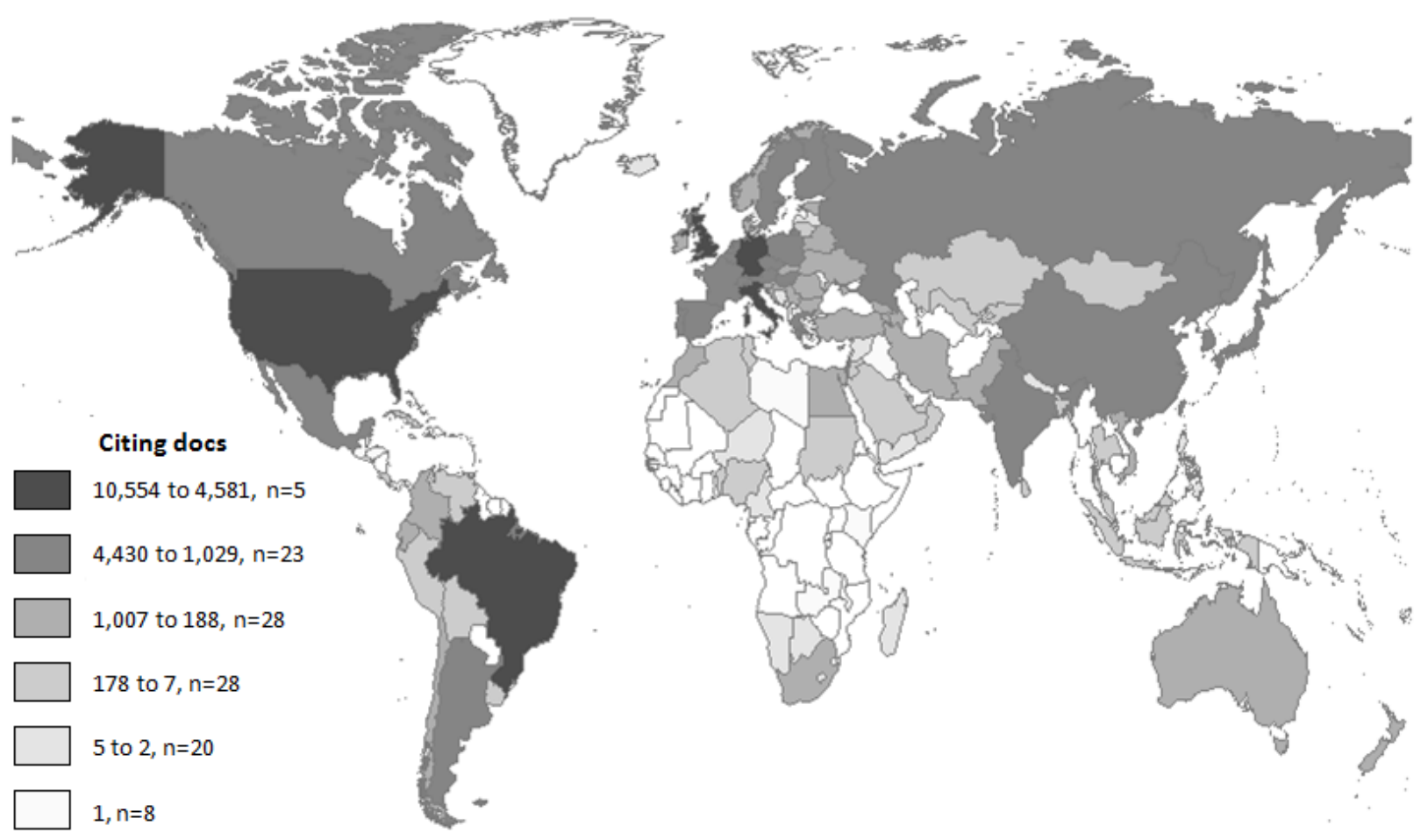

Figure 3 - Geographical distribution of citing documents (all types) for Brazilian HEP, 1983-2013.

Russia and France are the country's main partners. Relative indicators show decentralization and diversification in national collaborations. The high number of foreign researchers in citing documents (all types) underscores the global prestige and visibility of local production. The results of the analytical characterization suggest a maturation process in the Brazilian HEP community as a result of its long history in experimental research. Indeed, the status of Associate Member of CERN may boost Brazil's credibility in long-term projects, consolidate areas of expertise on instrumentation and data analysis tools (software programs), and enhance the influence of the countries science in the international arena. The scenario of highly internationalized HEP participation of Brazil follows the international trend in which productivity and impact are associated with large and multicultural groups.

\section{ACKNOWLEDGMENTS}

The authors would like to thank the Conselho Nacional de Desenvolvimento Científico e Tecnológico $(\mathrm{CNPq})$ for their financial support.

\section{REFERENCES}

ADAMS J AND KING C. 2009. Global Research Report: Brazil. Research and collaboration in the new geography of science. Leeds: Thomson Reuters.

ALE EBRAHIM N, SALEHI H, EMBI MA, HABIBI F, GHOLIZADEH H, MOTAHAR SM AND ORDI A. 2013. Effective strategies for increasing citation frequency. International Education Studies 6(11): 93-99.

ALMEIDA ECE AND GUIMARÃES JA. 2013. Brazil's growing production of scientific articles - how are we doing with review articles and other qualitative indicators? Scientometrics 97(2): 287-315.

AMAN V. 2013. The potential of preprints to accelerate scholarly communication: a bibliometric analysis based on selected journals (Doctoral thesis). Humboldt University of Berlin, Berlin, Germany, $97 \mathrm{p}$.

BONILLA-CALERO AIB. 2009. La colaboración y la visibilidad en las disciplinas de Física en Science Citation 
Index y arXiv (2000-2005) (Tesis doctoral). Universidad Carlos III de Madrid, Getafe, España, 476 p.

BORDONS M AND GÓMEZ I. 2000. Collaboration networked in science. In: Cronin B and Atkins HB (Eds), The web of knowledge: a festschrift in honor of Eugene Garfield, New Jersey: ASIS, p. 197-214.

BRAUN T, GÓMEZ I, MÉNDEZ A AND SCHUBERT A. 1992. International co-authorship patterns in physics and its subfields, 1981-1985. Scientometrics 24(2): 181-200.

CAPES - COORDENAÇÃO DE APERFEIÇOAMENTO DE PESSOAL DE NÍVEL SUPERIOR. 2013. Documento de área 2013. Brasília: CAPES.

CBPF - CENTRO BRASILEIRO DE PESQUISAS FÍSICAS. 2011. Plano Diretor do CBPF 2011-2015. Rio de Janeiro: CBPF.

CHOMPALOV I, GENUTH J AND SHRUM W. 2002. The organization of scientific collaborations. Research Policy 31: 749-767.

COLLAZO-REYES F AND LUNA-MORALES ME. 2002. Física mexicana de partículas elementales: organización, producción científica y crecimiento. Interciencia 27(7): 347-353.

COLLAZO-REYES F, LUNA-MORALES ME AND RUSSELL JM. 2004. Publication and citation patterns of the Mexican contribution to a "Big Science" discipline: Elementary Particle Physics. Scientometrics 60(2): 131143.

DUARTE RP. 2008. Cooperação internacional para o desenvolvimento em ciência e tecnologia: a participação brasileira na Organização Europeia para Pesquisa Nuclear (CERN). J Technol Manag Innov 3(4): 133-151.

HIRSCH JE. 2005. An index to quantify an individual's scientific research output. P Natl Acad Sci USA 102(46): 16569-16572.

JONES BF, WUCHTY S AND UZZI B. 2008. Multiuniversity research teams: shifting impact, geography, and stratification in science. Science 322(5905): 1259-1262.

KATZ JS. 1994. Geographical proximity and scientific collaboration. Scientometrics 31(1): 31-43.

KRAUSE J, LINDQVIST CM AND MELE S. 2007. Quantitative study of the geographical distribution of the authorship of High-Energy Physics journals (Report No. 2007-014). Geneva: European Organization for Nuclear Research.

KRETSCHMER H AND ROUSSEAU R. 2001. Author inflation leads to a breakdown of Lotka's law. J Assoc Inf Sci Tech 52(8): 610-614.

LEFEVRE C. 2007. Technology Transfer@ CERN: from research to everyday life. Geneva: European Organization for Nuclear Research.

LEHMANN S, LAUTRUP B AND JACKSON AD. 2003. Citation Networks in High Energy Physics. Phys Rev E 68(2): 26113-26118.
LÉPINE-SZILY A. 2011. Relatório sobre o acordo BrasilCERN. Available at http://www.sbfisica.org.br/v1/ arquivos_diversos/relatorios/2011/9_NUC_CERN.pdf Accessed on 25 Oct. 2015.

LETA J. 2011. Indicadores de desempenho, ciência brasileira e a cobertura das bases informacionais. Rev USP (89): 62-77.

LETA J. 2012. Brazilian growth in the mainstream Science: the role of human resources and national journals. J Scientometrics Res 1(1): 44-52.

LETA J AND CRUZ CH. 2003. A produção científica brasileira. In: Viotti EB and Macedo MM (Eds), Indicadores de Ciência, Tecnologia e Inovação no Brasil, Campinas: Universidade Estadual de Campinas, p. 121168.

LETA J, GLÄNZEL W AND THIJS B. 2006. Science in Brazil. Part 2: A macro-level comparative study. Scientometrics 67(1): 67-86.

LUUKKONEN T, TIJSSEN RJW, PERSSON O AND SIVERTSEN G. 1993. The measurement of international scientific collaboration. Scientometrics 28(1): 15-36.

MEADOWS J. 1999. A comunicação científica. Brasília: Briquet de Lemos.

MELE S, DALLMAN D, VIGEN J AND YEOMANS J. 2006. Quantitative analysis of the publishing landscape in HighEnergy Physics. J High Energy Phys 2006(12): 1-23.

MOTOYAMA S. 2004. Prelúdio para uma história: ciência e tecnologia no Brasil. São Paulo: Universidade de São Paulo.

NEWMAN MEJ. 2001a. The structure of scientific collaboration networks. P Natl Acad Sci USA 98(2): 404 409.

NEWMAN MEJ. 2001b. Scientific collaboration networks. I. Network construction and fundamental results. Phys Rev E 64(1): 1-8.

NEWMAN MEJ. 2001c. Scientific collaboration networks. II. Shortest paths, weighted networks, and centrality. Phys Rev E 64(1): 1-7.

NEWMAN MEJ. 2004. Coauthorship networks and patterns of scientific collaboration. P Natl Acad Sci USA 101(1): 5200-5205.

SANTORO AFS AND NOVAES SF. 2003. Física de Altas Energias: características e particularidades da área. Rio de Janeiro: Sociedade Brasileira de Física.

SBF - SOCIEDADE BRASILEIRA DE FÍSICA. 1987. A Física no Brasil. São Paulo: Sociedade Brasileira de Física.

SCHWARTZMAN S. 2001. Um espaço para a ciência: a formação da comunidade científica no Brasil. Brasília: Ministério da Ciência e Tecnologia.

SHELLARD RC. 2011. Física de Altas Energias no Brasil. Tlaxcala: Centro Brasileiro de Pesquisas Físicas. 
SIDONE OJG, HADDAD EA AND MENA-CHALCO JP. 2017. Scholarly publication and collaboration in Brazil: the role of geography. J Assoc Inf Sci Tech 68(1): 243-258.

SNPG - SISTEMA NACIONAL DE PÓS-GRADUAÇÃO. 2015. Cursos recomendados/reconhecidos e cadernos de indicadores. Brasília: CAPES.

VANZ SAS. 2009. As redes de colaboração científica no Brasil: (2004-2006) (Tese de doutorado). Universidade Federal do Rio Grande do Sul, Porto Alegre, Brasil, 204 p.
VANZ SAS AND STUMPF IRC. 2010. Colaboração científica: revisão teórico conceitual. Pespect Cienc Inf 15(2): 42-55. VARGAS RA, VANZ SAS AND STUMPF IRC. 2014. The role of national journals on the rise in Brazilian Agricultural Science publications in Web of Science. J Scientometrics Res 3(1): 28-36.

VIEIRA CL AND VIDEIRA AAP. 2007. História e historiografia da física no Brasil. Fênix 4(3): 1-27. 